\title{
Determination of Arsenic in Environment by Spectrophotometric Technique using Hydroxamic Acids
}

\author{
Seema Singh ${ }^{1}$, Jeena Harjit ${ }^{2}$, H.C. Kataria ${ }^{3}$ and Sulbha Amlathe ${ }^{4}$ \\ ${ }^{I}$ (Research scholar, Barkatullah University, Bhopal) \\ ${ }^{2}$ (Prof \& Head Chemistry department, T.I.E.I.T, Karond Gandhinagar Bhopal (M.P)-462038) \\ ${ }^{3}$ (Prof Govt. Geetanjali Girls P.G College Bhopal (M.P)-462038) \\ ${ }^{4}$ (Supervisor, Prof \& Head Chemistry department, B.U.I.T, Hoshangabad Road Bhopal (M.P)-462026)
}

\begin{abstract}
A simple, rapid, stable and sensitive direct visible spectrophotometric method has been developed for the determination of trace amount of arsenic in environmental samples of Bhopal city using N-PBHA, N-pClPBHA and N-p-ClPCHA, Arsenic (III) reacts with different hydroxamic acids and forms light pink to violet colored complex in acidic medium which were extracted in $n$ - hexane. The calibration graph was linear over the concentrationrange of 0.0003786-0.004164, 0.003786-0.06057 and 0.003786-0.04921 $\mu \mathrm{gml}^{-1}$ for N-Phenylbenzo-hydroxamic acid (N-PBHA), N-p-Chloro-phenyl- benzo-hydroxamic acid (N-p-ClPBHA) and N-pChloro-phenyl-cinnamohydroxamic acid (N-p-ClPCHA), respectively. The molar absorptivities were found to be $2.892 \times 10^{5}, 1.5973 \times 10^{4}$ and $2.0238 \times 10^{4} \mathrm{~L} \mathrm{~mol}^{-1} \mathrm{~cm}^{-1}$ for the three hydroxamic acids. The optimum reaction condition and other analytical parameter were evaluated.
\end{abstract}

Key words: Arsenic, Environmental samples, $N$-PBHA, N-p-ClPBHA, N-p-ClPCHA and Spectrophotometeric.

\section{Introduction}

Arsenic and its compounds are known as poisonous substances and are widely distributed in the earth crust. The compounds of arsenic in groundwater are found with both organic and inorganic moiety. The inorganic compounds of arsenic are about 100 times more toxic than the organic ones and are more prevalent in groundwater [1]. The major inorganic compounds of arsenic in natural water are pentavalent arsenate ions [As(V)] like $\mathrm{H}_{3} \mathrm{AsO}_{4}, \mathrm{H}_{2} \mathrm{AsO}_{4}{ }^{-}, \mathrm{HAsO}_{4}{ }^{2-}$ and $\mathrm{AsO}_{4}{ }^{3-}$ and trivalent arsenite ions [As(III)]: $\mathrm{H}_{3} \mathrm{AsO}_{3}, \mathrm{H}_{2} \mathrm{AsO}_{3}{ }^{-}$and $\mathrm{HAsO}_{3}{ }^{2-}$ with the later being more toxic [2]. Under oxygenated condition arsenate is more common in oxygenated water while arsenite is found in anaerobic or highly reducing conditions [3]. The toxicity of arsenic is dependent on its molecular forms with inorganic species being the most toxic forms. Various health problems due to their presence include stomach pain, nausea, vomiting, diarrhea, etc. The long-term exposure of arsenic in drinking water increases the risk of cancer of skin, kidney, liver, and prostate. Moreover, it also disturbs the functioning of nervous and cardiovascular system and eventually leads to death [4, 5].

Arsenic concentration in various water bodies is increasing day to day due to several reasons like use of arsenical pesticides, mineral dissolution, mine drainage, disposal of fly ash, and geothermal discharge [6]. Due to its high toxicity, World Health Organization (WHO) has lowered the maximum contaminant level (MCL) for arsenic in drinking water from 50 to $10 \mu \mathrm{gL}^{-1}$ [7].

There are several accepted analytical methods currently available for arsenic measurement in environmental samples. These include polarographic speciation[8], colorimetric analysis [9] multisyringe flow injection system with hydride generation-atomic fluorescence [10], atomic absorption spectroscopy [11, 12], HPLC coupled HG-AAS[13], dispersive liquid-liquid microextraction combined with graphite furnace atomic absorption spectrometry [14], electrothermal atomic absorption spectrometry [15], electrospray ionization mass spectrometry [16], electrochemical detection[17] and atomic fluorescence spectrometry[18].

Spectrophotometric determination of arsenic using hexamethylene ammonium-hexamethylenedithiocarbamate [19], silver diethylthiocarbamate[20], azure-B([21], molybdate-iodine tetrachloride [22], variamine blue[23], rhodamine-B [24] have also been reported. Studies have been also done on determination of arsenic from aqueous solution by electro coagulation method using Al-Fe electrodes [25]. PVC based 5, 10, 5, 20tetrakis - (4-methoxyphenyl)-porphyrinatocobalt (II) membrane potentiometric sensor for arsenite has also been described [26]. MATLAB assisted disposable sensors for quantitative determination of arsenic was constructed by immobilizing reagents on TLC (thin layer chromatography) paper [27].

In the present investigation, the determination of trace arsenic in water by spectrophotometric method has been reported. This method is rapid, simple and based on use of non-toxic chemicals. Determination of trace amount of arsenic by this method is important because ground water, waste water and soil samples could be analysed in short period of time as compared to other spectrophotometic methods. 


\subsection{Instruments}

\section{Experimental}

"Shimadzu spectrophotomter1700" was used for electronic spectral measurements with $10 \mathrm{~mm}$ matched quartz cells. A Hanna 8521 model $\mathrm{pH}$ meter was used for $\mathrm{pH}$ measurements.

\subsection{Reagents and chemicals}

All the chemicals were of analytical grade. Stock standard solution of arsenic was made from arsenic tri- oxide. Working standard was prepared by appropriate dilution of stock solution. Aqueous solution of $2 \%$ potassium iodide was prepared by dissolving $2 \mathrm{~g} \mathrm{KI}$ in $100 \mathrm{ml}$ double distilled water. N-PBHA, N-p-ClPBHA and $\mathrm{N}$-p-ClPCHA stock solutions were prepared by dissolving $0.1 \mathrm{~g}$ of respective hydroxamic acid in $100 \mathrm{ml} \mathrm{n}$ hexane. Double distilled de-ionized water was used for preparation of standard solutions, dilution and washing vessels.

\section{Procedure}

The calibration curve was obtained by the following method: An aliquot of the sample solution containing $0.0003786-0.004164,0.003786-0.06057$ and $0.003786-$ $0.04921 \mu \mathrm{gml}^{-1}$ of arsenic for N-PBHA, N-p-ClPBHA and N-p-CIPCHA, respectively was transferred to a series of $25 \mathrm{ml}$ calibrating flask. In this solution, $1.5 \mathrm{ml}$ of $2 \%$ potassium iodide and $1 \mathrm{ml}$ of $1 \mathrm{M} \mathrm{HCl}$ were added and mixture was gently shaken until the appearance of yellow color which indicates the liberation of iodine. $1 \mathrm{ml}$ of $2 \%$ EDTA was then added for masking the interfering ions. Finally, $1 \mathrm{ml}$ of all the three hydroxamic acid solutions were added, light pink to violet colour was obtained immediately with different hydroxamic acids. The solution was kept for 2 minutes. A blank solution was prepared exactly in the same manner as test solution but without addition of arsenic. The absorbance of the sample solution was determined against the blank at $530 \mathrm{~nm}$, $508 \mathrm{~nm}$ and $520 \mathrm{~nm}$, respectively with three hydroxamic acids. The $\mathrm{pH}$ was maintained at 3.5 for N-PBHA, Np-ClPBHA and N-p-ClPCHA with drop wise addition of buffer solution. The amount of the arsenic present in the volume taken was computed from the calibration graph.

\section{Expected Reactions[28]}

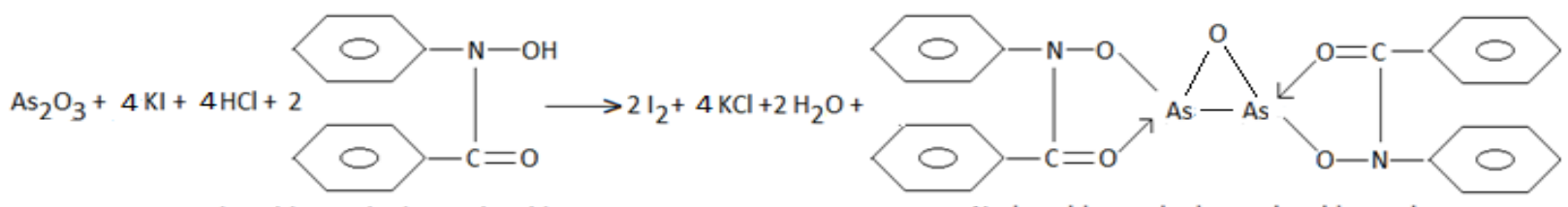

$\mathrm{N}$-phenyl-benzo-hydroxamic acid

$\mathrm{N}$-phenyl-benzo-hydroxamic acid complex

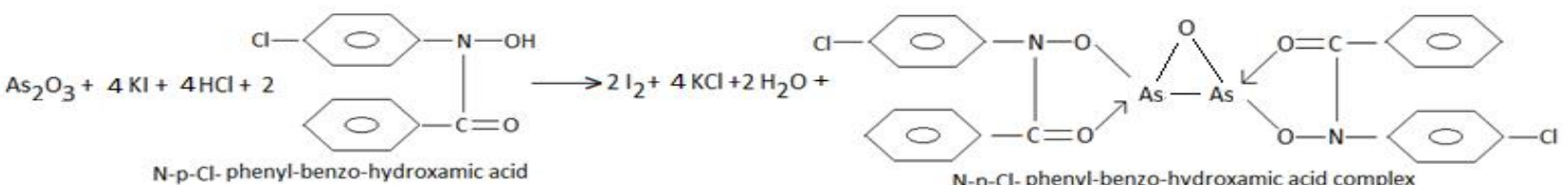

$\mathrm{N}$-p-Cl-phenyl-benzo-hydroxamic acid

$\mathrm{N}$-p-Cl-phenyl-benzo-hydroxamic acid complex

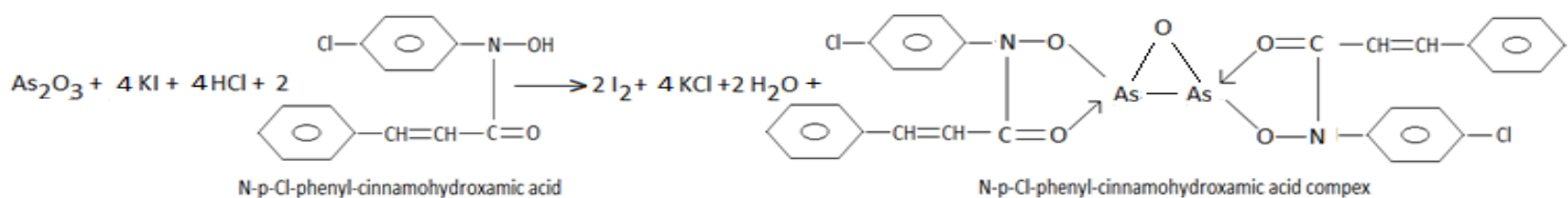

\section{Results and discussion}

\subsection{Absorption spectrum and calibration curve}

After reaction, complex present in organic phase was scanned from $400 \mathrm{~nm}$ to $600 \mathrm{~nm}$ against reagent blank (Fig.1). Maximum absorption values were observed at $530 \mathrm{~nm}, 508 \mathrm{~nm}$ and $520 \mathrm{~nm}$ for arsenic complex with N-PBHA, N-p-CIPBHA and N-p-ClPCHA, respectively. Therefore, $530 \mathrm{~nm}, 508 \mathrm{~nm}$ and $520 \mathrm{~nm}$ were selected with N-PBHA, N-p-ClPBHA and N-p-ClPCHA, respectively for the absorbance measurement throughout the experiments.

A calibration plot of absorbance against concentration of N-PBHA, N-p-ClPBHA and N-p-ClPCHA complexes at the absorption maxima gave a linear and reproducible graph in the concentration range of 0.0003786 -

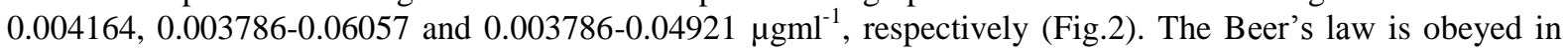
this range. Optical characteristics, precision and accuracy of the proposed method are summarized in Table 1. 


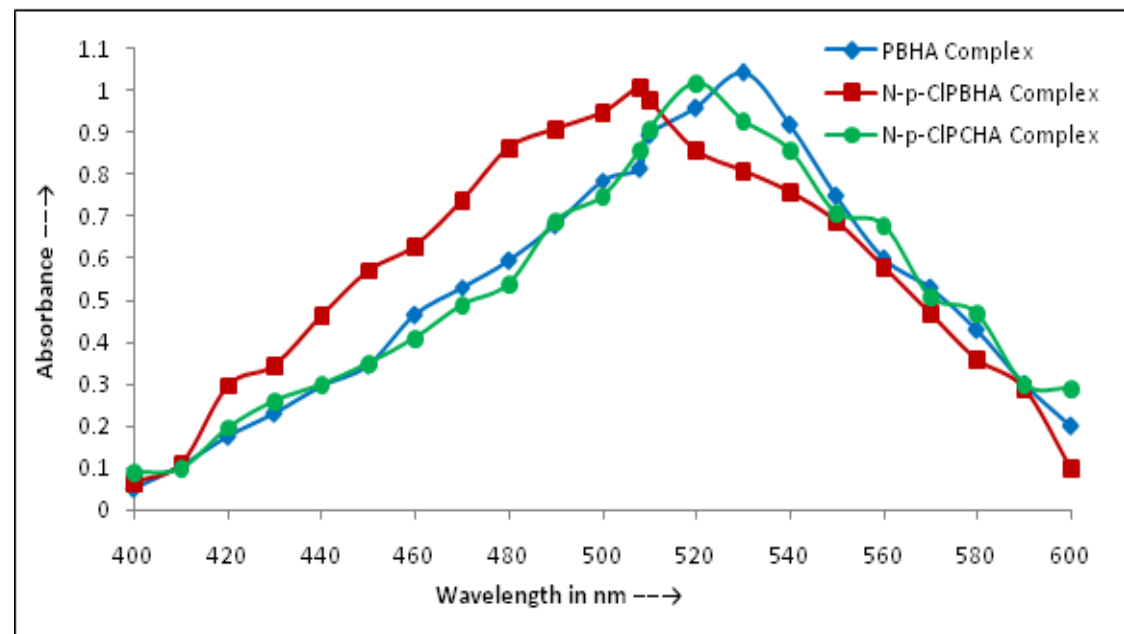

Figure1. Absorption spectra of arsenic complexes with hydroxamic acids

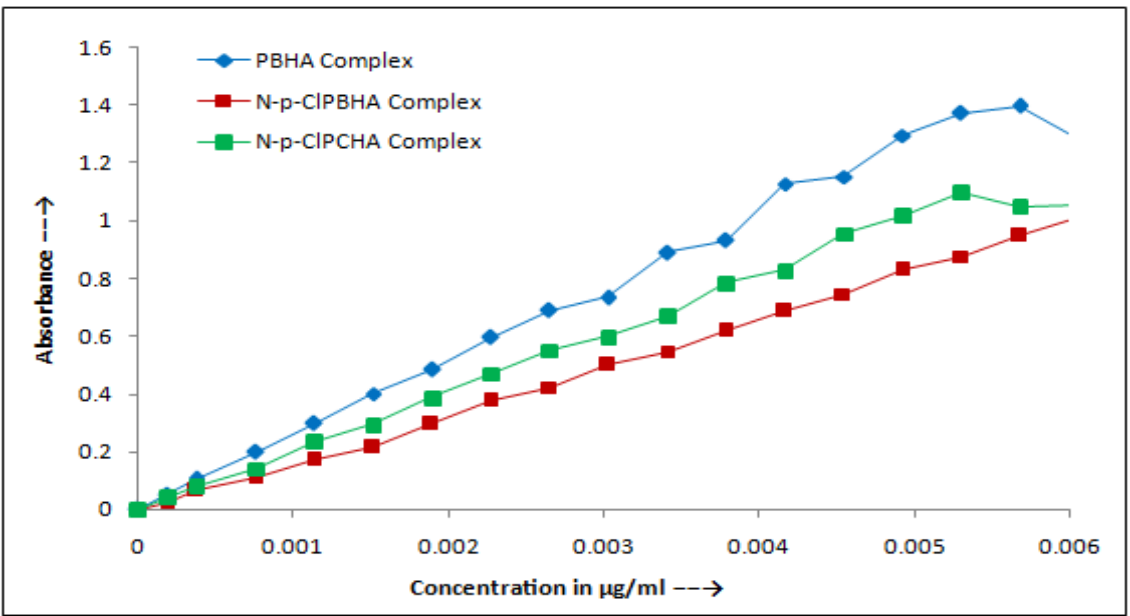

Figure2: Calibration plot for arsenic complexes with N-PBHA, N-p-ClPBHA and N-p-ClPCHA

Table 1: Optical characteristics, precision and accuracy of the proposed method

\begin{tabular}{|l|c|c|c|}
\hline & N-PBHA & N-p-CIPBHA & N-p-CIPCHA \\
\hline$\lambda$ max, nm & 530 & 508 & 520 \\
\hline $\begin{array}{l}\text { Beer's law limits in concentration range } \mu \mathrm{g} \\
\mathrm{ml}^{-1}\end{array}$ & $0.0003786-0.004164$ & $0.003786-0.06057$ & $0.003786-0.04921$ \\
\hline${\text { Molar absorptivity, } \mathrm{mol}^{-1} \mathrm{~cm}^{-1}}^{-2}$ & $2.892 \times 10^{5}$, & $1.5973 \times 10^{4}$ & $2.0238 \times 10^{4}$ \\
\hline $\begin{array}{l}\text { Sandell's sensitivity, } \mu \mathrm{g} \mathrm{cm} \\
0.001 \text { absorbance unit }\end{array}$ & $3.60 \times 10^{-6}$ & $6.76 \times 10^{-5}$ & $5.40 \times 10^{-5}$ \\
\hline Limit of detection, $\mu \mathrm{g} \mathrm{ml}{ }^{-1}$ & $8.432 \times 10^{-5}$ & $8.956 \times 10^{-4}$ & $9.585 \times 10^{-4}$ \\
\hline Relative standard deviation $\%$ & 1.5 & 1.9 & 1.6 \\
\hline Quantitation limit $\mu \mathrm{g} \mathrm{ml} \mathrm{m}^{-1}$ & $2.55 \times 10^{-4}$ & $2.714 \times 10^{-3}$ & $2.904 \times 10^{-3}$ \\
\hline
\end{tabular}

\subsection{Effect of iodide concentration and acidity}

The effect of iodide concentration and acidity on the color intensity was studied with given concentration range of arsenic solution. The appearance of yellow color indicates the liberation of iodine. Although any excess of iodine in the solution will not interfere. It is found that $1 \mathrm{ml}$ of $2 \%$ potassium iodide and $1 \mathrm{ml}$ of $1 \mathrm{M} \mathrm{HCl}$ are sufficient for completion of reaction. In order to obtain the optimum condition for the determination of arsenic, absorbance was measured at the $\mathrm{pH}$ range $1.0-10.0$. Constant and maximum absorbance values were obtained at the $\mathrm{pH}=3.5 \pm 0.2$. Hence, the $\mathrm{pH}$ of the reaction system is maintained at $3.5 \pm 0.2$ throughout the study. This could be achieved by the addition of $2 \mathrm{ml}$ of $1 \mathrm{M}$ sodium acetate solution in a total volume of $25 \mathrm{ml}$ (Fig. 3.) 


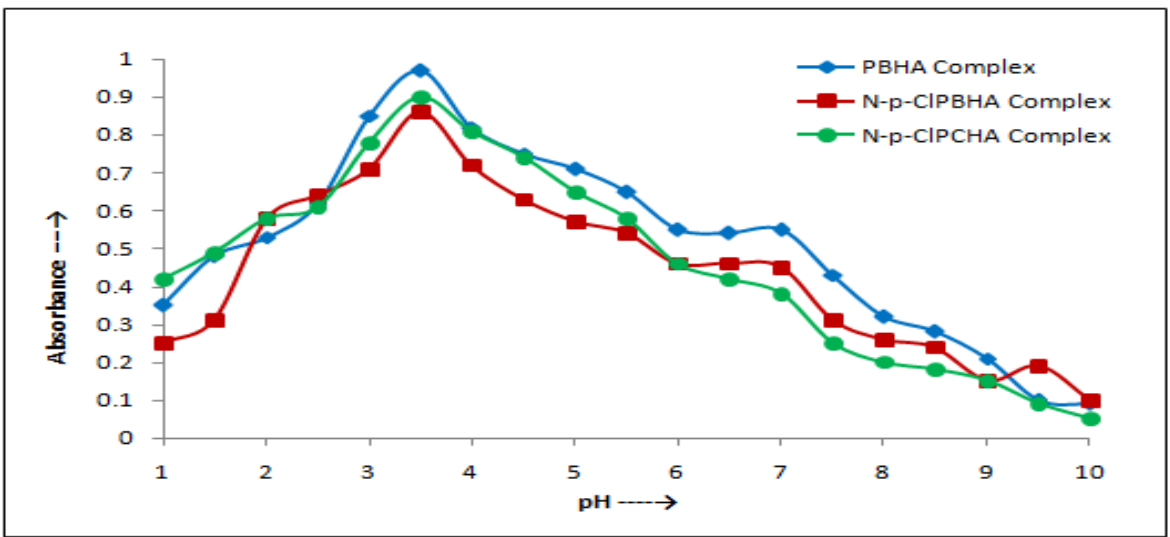

Figure3: Effect of $\mathrm{pH}$ on absorbance of complexes

\subsection{Effect of different solvent}

Different organic solvents like ethanol, n-butanol, diethyl ether, ethyl-methyl ketone, ethyl acetate, chloroform, toluene, $\mathrm{n}$ - hexane and carbon tetrachloride were used for determination. $\mathrm{n}$ - hexane was found to be most suitable solvent as it gave better and quick phase separation. Therefore, $\mathrm{n}$ - hexane was selected.

\subsection{Effect of reagent concentration}

Optimal concentration of hydroxamic acids were investigated by varying the amount of hydroxamic acids used as a reagent. To a series of arsenic standard solution, varying concentration of various hydroxamic acids solutions were added and mixed. It was observed that the absorbance increases with increasing the concentration of hydroxamic acids .It is found that maximum absorbance was observed at $1.5 \mathrm{ml}, 2 \mathrm{ml}$ and $3 \mathrm{ml}$ of $0.0001 \%$ of N-PBHA, N-p-CIPBHA and N-p-CIPCHA hydroxamic acids solutions, respectively. After which it decreases rapidly. Therefore, the above mentioned volume was selected for these hydroxamic acids for all experiments (Fig. 4).

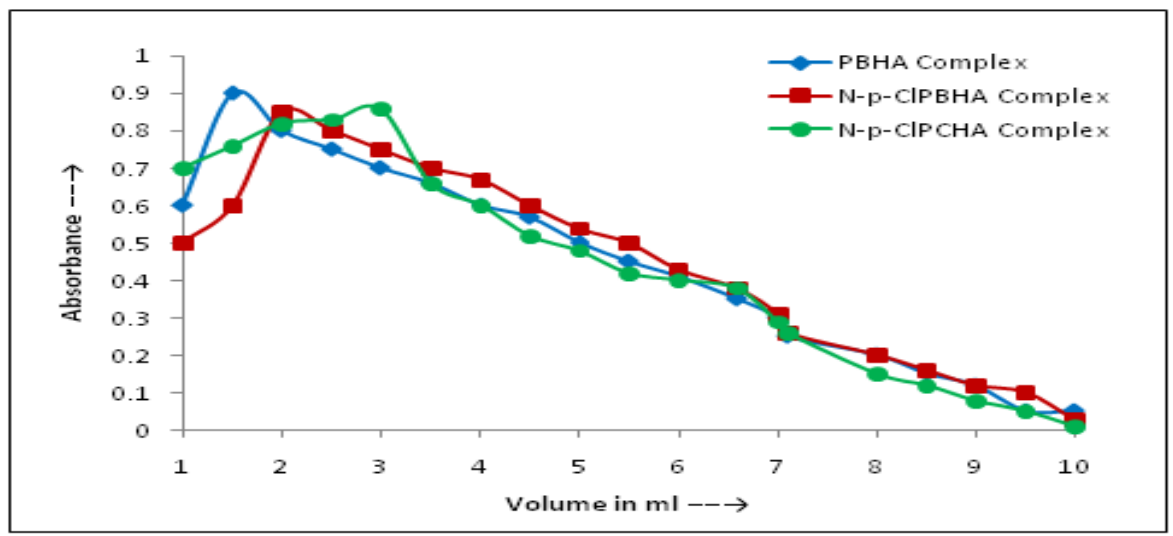

Figure4: Effect of reagent concentration on absorbance of complexes

\subsection{Effect of temperature}

The effect of temperature on absorbance of the complex was studied over the temperature range of $1^{\circ} \mathrm{C}$ $-60^{\circ} \mathrm{C}$. It was observed that reaction becomes very fast at the room temperature and formed complexes gives maximum and stable absorption at the temperature of $30^{\circ} \mathrm{C}, 25^{\circ} \mathrm{C}$ and $22^{\circ} \mathrm{C}$ for N-PBHA, N-p-ClPBHA and Np-CIPCHA, respectively. Therefore, all experiments performed at the above temperature (Fig.5). 


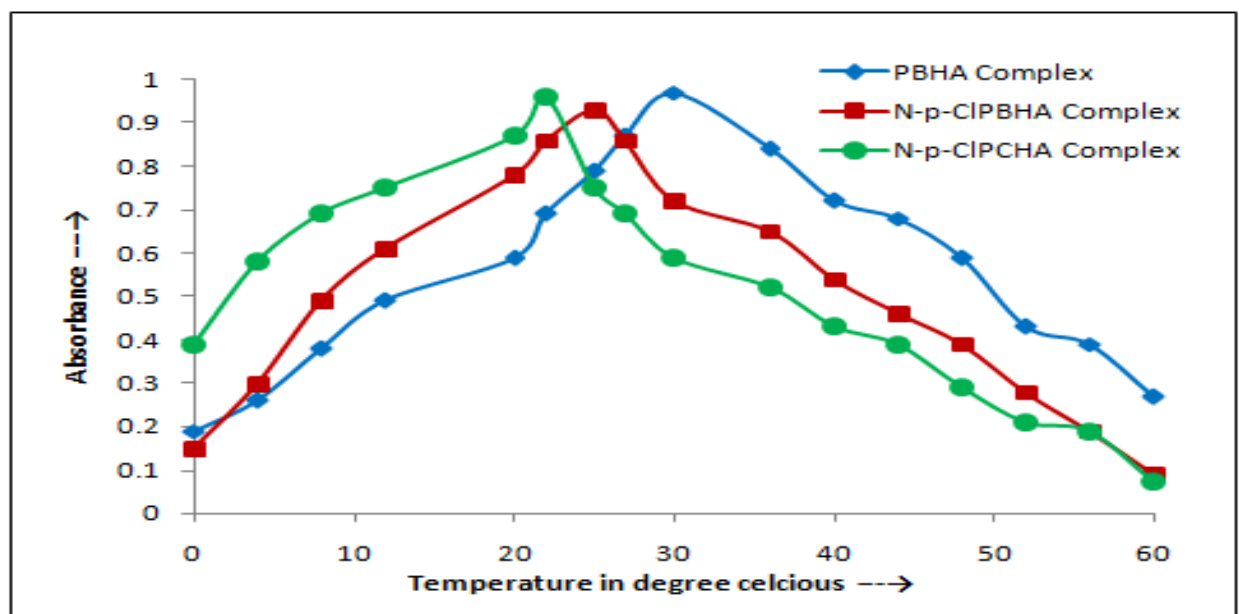

Figure 5: Effect of temperature on absorbance of complexes

\subsection{Effect of stirring time and rest time}

Effect of stirring time and rest time was also studied. For studying the effect of stirring time, the absorbance of formed complex was studied and compared. The stirring time was varied from 0-90seconds. As it is clear, after about 40, 55, 64 seconds of stirring and 10seconds of rest time, the formed complex gives maximum absorption. Therefore above stirring and rest time selected in subsequent studies (Fig. 6).

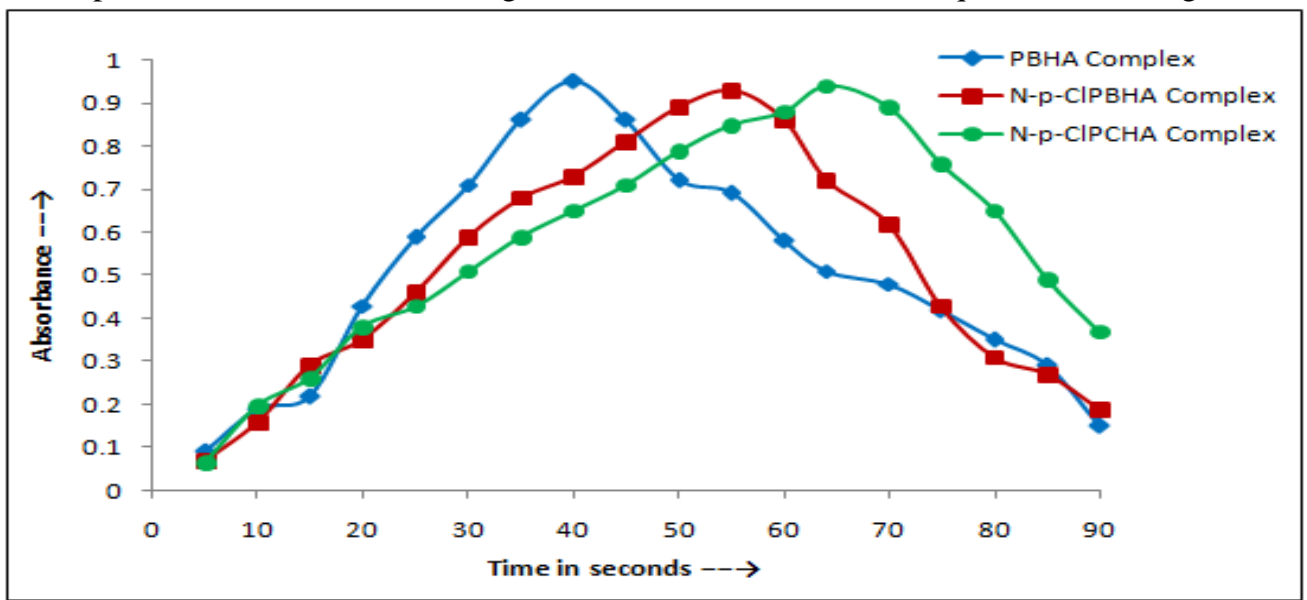

Figure6: Effect of reaction time on absorbance of complexes

\subsection{Effect of foreign ions}

The effect of various foreign ions at microgram levels on the determination of arsenic using different hydroxamic acids were studied. The tolerance limits of interfering species were established at the concentration that do not cause more than $\pm 1.0 \%$ error in absorbance values for arsenic(III) at $0.0003786-0.004164,0.003786$ 0.06057 and $0.003786-0.04921 \mu \mathrm{gml}^{-1}$ for N-PBHA, N-p-ClPBHA and N-p-ClPCHA, respectively. The results indicated that most of the common ions did not interfere Table 2.

Table2: Effect of foreign ions on the determination of arsenic

\begin{tabular}{|c|c|c|c|c|}
\hline \multirow{2}{*}{$\mathrm{S} \mathrm{No}$} & \multirow{2}{*}{ Diverse ions } & \multicolumn{3}{|c|}{ Tolerance limit $\left(\mu \mathrm{gL}^{-1}\right)$} \\
\cline { 3 - 5 } & $\mathrm{Al}^{3+}$ & N-PBHA & N-p-ClPBHA & N-p-ClPCHA \\
\hline 1 & $\mathrm{Ba}^{2+}$ & 600 & 400 & 370 \\
\hline 2 & $\mathrm{Ca}^{2+}$ & 900 & 850 & 300 \\
\hline 3 & $\mathrm{Cd}^{2+}$ & 420 & 610 & 520 \\
\hline 4 & $\mathrm{Co}^{2+}$ & 550 & 168 & 150 \\
\hline 5 & $\mathrm{~V}^{5+}$ & 170 & 146 & 140 \\
\hline 6 & $\mathrm{Zn}^{2+}$ & 150 & 900 & 850 \\
\hline 7 & $\mathrm{Cu}^{2+*}$ & 1050 & 100 & 111 \\
\hline 8 & $\mathrm{Fe}^{3+*}$ & 140 & 105 & 750 \\
\hline 9 & $\mathrm{Bi}^{3+}$ & 950 & 1000 & 700 \\
\hline 10 & $\mathrm{PO}_{4}^{3-}$ & 1000 & 960 & 155 \\
\hline 11 & $\mathrm{Mg}^{2+}$ & 160 & 163 & \\
\hline 12 & & & & \\
\hline
\end{tabular}


Determination of Arsenic in Environment by Spectrophotometric Technique using Hydroxamic Acids

\begin{tabular}{|c|c|c|c|c|}
\hline 13 & $\mathrm{Mn}^{2+}$ & 120 & 105 & 110 \\
\hline 14 & $\mathrm{Na}^{+}$ & 500 & 450 & 430 \\
\hline 15 & $\mathrm{~K}^{+}$ & 800 & 810 & 797 \\
\hline 16 & $\mathrm{SO}_{4}{ }^{2-}$ & 900 & 820 & 760 \\
\hline 17 & $\mathrm{C}_{2} \mathrm{O}_{4}{ }^{2-}$ & 1050 & 805 & 7000 \\
\hline 18 & $\mathrm{Ni}^{2+}$ & 120 & 680 & 75 \\
\hline 19 & $\mathrm{NO}_{3}{ }^{-}$ & 700 & 1225 & 1000 \\
\hline 20 & $\mathrm{C}_{4} \mathrm{H}_{4} \mathrm{O}_{6}{ }^{2-}$ & 1300 & & \\
\hline
\end{tabular}

* Masked by EDTA

Table 3: Determination and recovery of arsenic in water and soil samples

\begin{tabular}{|c|c|c|c|c|c|c|c|c|}
\hline \multirow{2}{*}{$\begin{array}{l}\text { S } \\
\text { No. }\end{array}$} & \multirow{2}{*}{$\begin{array}{l}\text { Locations in } \\
\text { Bhopal }\end{array}$} & \multirow{2}{*}{$\begin{array}{l}\mathrm{As}^{3+} \text { added } \\
\left(\mu \mathrm{gL}^{-1}\right)\end{array}$} & \multicolumn{3}{|c|}{$\mathrm{As}^{3+}$ found } & \multicolumn{3}{|c|}{ Recovery $\%$} \\
\hline & & & $\begin{array}{l}\mathrm{N}- \\
\mathrm{PBHA}\end{array}$ & N-p-ClPBHA & N-p-CIPCHA & N-PBHA & N-p-ClPBHA & N-p-ClPCHA \\
\hline \multirow[t]{2}{*}{1} & \multirow{2}{*}{ GI } & 0.00 & 3.7 & 3.3 & 2.9 & ----- & ----- & ----- \\
\hline & & 2.00 & 5.68 & 5.26 & 4.80 & 99.6 & 99.2 & 97.9 \\
\hline \multirow[t]{2}{*}{2} & \multirow{2}{*}{ MI } & 0.00 & 3.9 & 3.2 & 3.7 & ---- & ---- & ---- \\
\hline & & 2.00 & 5.75 & 5.18 & 5.68 & 97.4 & 99.6 & 99.6 \\
\hline \multirow[t]{2}{*}{3} & \multirow{2}{*}{ SL } & 0.00 & 2.7 & 2.6 & 2.4 & ----- & ----- & ----- \\
\hline & & 2.00 & 4.69 & 4.55 & 4.37 & 99.7 & 98.9 & 98.3 \\
\hline \multirow[t]{2}{*}{4} & \multirow{2}{*}{ UL } & 0.00 & 2.6 & 2.4 & 2.3 & ----- & --- & ----- \\
\hline & & 2.00 & 4.58 & 4.35 & 4.24 & 99.5 & 98.8 & 98.6 \\
\hline \multirow[t]{2}{*}{5} & \multirow{2}{*}{$\mathrm{LL}$} & 0.00 & 2.3 & 1.8 & 2.1 & ----- & ----- & ----- \\
\hline & & 2.00 & 4.29 & 3.68 & 4.05 & 99.7 & 96.8 & 98.7 \\
\hline \multirow[t]{2}{*}{6} & \multirow{2}{*}{ ANUC } & 0.00 & 2.5 & 1.8 & 1.6 & ----- & ----- & ----- \\
\hline & & 2.00 & 4.44 & 3.70 & 3.48 & 98.6 & 97.3 & 96.6 \\
\hline \multirow[t]{2}{*}{7} & \multirow{2}{*}{$\mathrm{KD}$} & 0.00 & 1.3 & 1.1 & 1.2 & ----- & ----- & ----- \\
\hline & & 2.00 & 3.28 & 3.05 & 3.14 & 99.3 & 98.3 & 98.12 \\
\hline \multirow[t]{2}{*}{8} & \multirow[b]{2}{*}{$\begin{array}{l}\text { Soil } \\
\text { Samples }\end{array}$} & 0.00 & 1.46 & 1.55 & 1.48 & $\begin{array}{l}----- \\
\end{array}$ & ----- & ------ \\
\hline & & 2.00 & 3.42 & 3.51 & 3.4 & 98.84 & 98.87 & 97.7 \\
\hline
\end{tabular}

GI-Govindpura industrial area, MI- Mandideep Industrial area, SL- Shahpura Lake, UL- Upper Lake, LLLower lake, ANUC- Area Near Union Carbide, KD- Kolar Dam

\subsection{Determination of arsenic in polluted water samples}

\section{Applications of the method}

Environmental exposure to arsenic has an important public health concern and is receiving increasing attention. However, there is a scarcity of data available on arsenic geochemistry in Bhopal city. In order to investigate the applicability of this procedure to water and soil samples, the recoveries of known amounts of arsenic added to water samples were examined by the proposed procedure.

The water samples were collected from different areas of Bhopal district in polyethylene bottles, which were filtered through whatmann 42 filter paper. The arsenic levels found (1.1-3.9 $\mu \mathrm{gL}-1)$ showed that high concentration (more than permissible limit) of arsenic is not present in the investigating areas. Arsenic recovery was measured using a standard addition method. The results are given in Table 3, EDTA was used to eliminate the interferences. Recovery of arsenic varied from 96.6 to $99.7 \%$. These results summarized in Table 3 demonstrate that the proposed procedure is applicable for arsenic analysis in different water samples and soil with a satisfactory recovery.

\subsection{Determination of arsenic in soil samples}

A known weight $(1 \mathrm{~g})$ of a soil sludge sample was placed in a $50 \mathrm{ml}$ beaker and extracted 4 times with a $5 \mathrm{ml}$ portion of concentrated $\mathrm{HCl}$. The solution was evaporated at a low temperature $\left(<100^{\circ}\right)$ for about 30 minutes. Because of a possible presence of organically bound arsenic, a digestion step must be included to ensure conversion of total arsenic to an inorganic form. The solution was cooled and diluted to 25 ml volumetric flask with distilled water. Suitable aliquot of the sample was analyzed by the proposed method.

The proposed method is compared with other spectrophotometric methods in Table 4

Table 4: Comparison with other methods

\begin{tabular}{|c|c|c|c|c|}
\hline $\begin{array}{c}\text { S. } \\
\text { no }\end{array}$ & Reagents/reference & $\lambda \max , \mathrm{nm}$ & $\begin{array}{c}\text { Range of determination, } \\
\mathrm{mgL}^{-1}\end{array}$ & Remarks \\
\hline 1 & $\begin{array}{c}\text { Hexamethylene Ammonium- } \\
\text { Hexamethylenedithiocarbamate [19] }\end{array}$ & 256 & $0.2-1.0$ & $\begin{array}{c}\text { Sensitive, simple, rapid; free from } \\
\text { common interference }\end{array}$ \\
\hline 2 & $\begin{array}{c}\text { Silver diethyldithiocarbamate - Tritron- } \\
\text { X[20] }\end{array}$ & 540 & $0.05-2.80$ & non-ionic surfactant required \\
\hline 3 & Azure- B [21] & 664 & $0.2-10$ & Less sensitive \\
\hline
\end{tabular}


Determination of Arsenic in Environment by Spectrophotometric Technique using Hydroxamic Acids

\begin{tabular}{|c|c|c|c|c}
\hline 4 & Variamine blue[23] & 556 & $0.2-14$ & Less sensitive \\
\hline 5 & Rhodamine-B[24] & 553 & $0.04-0.4$ & $\begin{array}{c}\text { Based on bleaching of dye i.e. } \\
\text { (indirect method) }\end{array}$ \\
\hline 6 & $\begin{array}{c}\text { Ammonium molybdate + } \\
\text { sodiummetavanadate [29] }\end{array}$ & 460 & $1-30$ & $\begin{array}{c}\text { Phosphorus, silicon, interfere; less } \\
\text { sensitive }\end{array}$ \\
\hline 7 & Oleic acid surfactant [30] & 435 & $0.25-20$ & Indirect reaction \\
\hline 8 & $\begin{array}{c}2-(5-b r o m o-2-p y r i d y l a z 0)-5-d i- \\
\text { ethylaminophenol (Br-PADAP) [31] }\end{array}$ & 560 & $\begin{array}{c}\text { Complexing reagent was formed } \\
\text { within reaction so it is time taking } \\
\text { method. }\end{array}$ \\
\hline 9 & $\begin{array}{c}\text { Different hydroxamic acids: N-PBHA, N-p- } \\
\text { ClPBHA and N-p-ClPCHA (Proposed } \\
\text { method) }\end{array}$ & $\begin{array}{c}530 \mathrm{~nm}, 508 \\
\mathrm{~nm} \mathrm{520} \mathrm{nm}\end{array}$ & $\begin{array}{c}0.0003786-0.004164, \\
0.003786-0.06057, \\
0.003786-0.04921\end{array}$ & $\begin{array}{c}\text { Sensitive, simple, rapid; free from } \\
\text { common interference, colour is } \\
\text { stable for several days. }\end{array}$ \\
\hline
\end{tabular}

\section{Conclusions}

The proposed procedure provides a selective, accurate and precise method for the determination of arsenic in environmental samples. This suggested method could be used for rapid and simple determination of As (III) in water samples. The results of analysis of samples are very close to those obtained by the other common methods. Our method has enormous practical potential for simple detection of arsenic, including field conditions which require no complex equipment or skilled laboratory support. As seen in figures this method based on using various hydroxamic acids are very suitable for the analysis of natural samples. These chelating agents have been used before to determine other metals with different methods but this is their first application to determine arsenic in environment of Bhopal district.

\section{References}

[1]. C.K. Jain, I. Ali, Arsenic: occurrence, toxicity and speciation techniques, Wat. Res., 34, 2000, 4304- 4312

[2]. J.O. Nriagu, Arsenic in the Environment. Part I: Cycling and Characterization. John Wiley \& Sons, Inc, New York, 1994.

[3]. J. Colloid Interface Sci., 353( 1), 2011, 257- 262.

[4]. I. Ali, T.A. Khan, M. Asim, Removal of Arsenic from Water by Electrocoagulation and Electrodialysis

[5]. Techniques, Separation and Purification Rev., 40(1), 2011, 25 - 42

[6]. K.A. Graeme, and C.V. Pollack, Heavy metal toxicity. Part I: Arsenic and mercury,J. Emerg. Med., 16(1), $1998,45-56$.

[7]. E.A Murphy, M Aucott, An assessment of the amounts of arsenical pesticides used historically in a geographical area,Science of The Total Environment, 218( 2-3), 1998, 89-101.

[8]. WHO 2001 Arsenic in drinking water. United Nations Synthesis Report on Arsenic In Drinking Water: http://www.who.int/mediacentre/factsheets/fs210/en/

[9]. U.Unal, G.Somer,A new and simple procedure for the polarographic speciation and determination of trace inorganic As(III) and As(V) species, Turk J Chem, 35, 2011, 779 - 792.

[10]. O.Agraawal, G. Sunita and V. K. Gupta, A Sensitive Colorimetric Method for the Determination of Arsenic in Environmental and Biological Samples, Journal of the Chinese Chemical Society, 46,1999,641-645.

[11]. L.O. Leal, R. Forteza, V. Cerda, Speciation analysis of inorganic arsenic by a multisyringe flow injection system with hydride generation-atomic fluorescence spectrometric detection,Talanta, 69(2),2006, 500-508.

[12]. S.Maity, S.Chakravarty, P. Thakur, K.K. Gupta, S. Bhattacharjee and B.C. Roy,Evalution and Standardisation of a simple HG-AAS in some contaminated Groundwater Samples of West Bengal, India,Chemosphere, 54 (8), 2004, 1199-1206.

[13]. P. Niedzielski, M. Siepak, J. Przybyłek, J. Siepak, Atomic Absorption Spectrometry in Determination of Arsenic, Antimony and Selenium in Environmental Samples, Polish Journal of Environmental Studies, 11(5), 2002, 457-466.

[14]. J. L. Gomez-Ariza, D. Sanchez-Rodas and I. Giraldez, Selective extraction of iron oxide associated arsenic species from sediments for speciation with coupled HPLC-HG-AAS,J.Anal. At.Spectrom, 13, 1998, 1375-1379.

[15]. Ricardo E. Rivas, Ignacio Lopez-Garcia, Manuel Hernandez-Cordoba, Speciation of very low amounts of Arsenic and Antimony in Water using Dispersive Liquid- Liquid Microextraction and Electrothermal Atomic Absorption Spectrometry, SpectrochimicaActa Part B: Atomic Spectroscopy, 64( 4), 2009, 329-333.

[16]. H.M. Anawar, Arsenic speciation in environmental samples by hydride generation and electrothermal atomic absorption spectrometry,Talanta, 88, 2012, 30-42.

[17]. K. Minakata, M. Suzuki andO. Suzuki, Simple and selective determination of arsenite and arsenate by electrospray ionization mass spectrometry,Anal ChimActa.,631(1),2009, 87-90.

[18]. R.Muniyandi, S. Thiagarajan, S.M. Chen, Electrochemical Detection of Arsenic in Various Water Samples,Int. J. Electrochem. Sci., 6,2011, $3164-3177$

[19]. L Rahman, W.T Corns, D.W Bryce, P.B Stockwell, Determination of mercury, selenium, bismuth, arsenic and antimony in human hair by microwave digestion atomic fluorescence spectrometry, Talanta, 52( 5), 2000, 833-843.

[20]. S.Karayunlu and U. Ay, Spectrophotometric Determination of Total Inorganic Arsenic with HexamethyleneAmmoniumHexamethylenedithiocarbamate in Nonionic Triton X-100 Micellar Media, Journal of Analytical Chemistry, 65(3), 2010, 244-248.

[21]. S. G. Aggarwal, B. D. Diwana, S. Agarwal, V. K. Gupta and G. L. Mundhara, Speciation of Arsenic in Environmental and Biological Samples, Journal of the Chinese Chemical Society, 49, 2002, 553-559.

[22]. T. Cherian and B. Narayana, A New Spectrophotometric Method for the Determination of Arsenic in Environmental and Biological Samples,Anal. Lett.,38,2005,2207- 2216

[23]. K. Morita, E. Kaneko, Spectrophotometric Determination of Trace Arsenic in Water Samples Using a Nanoparticle of Ethyl Violet with a Molybdate-Iodine Tetrachloride Complex as a Probe for MolybdoarsenateAnal Chem.,78(22), 2006, $7682-7688$.

[24]. B.Narayana, Tom Cherian et al., Spectrophotometric determination of arsenic in environmental and biological samples,Indian Journal of Chemical Technology, 13, 2006, 36-40. 
[25]. A.Pillai, G.Sunita and V. K Gupta, A new system for the spectrophotometric determination of arsenic in environmental and biological samples, AnalyticaChimicaActa, 408(1), 2000, 111-115.

[26]. I. Ali, V. K Gupta, T. A Khan and MohdAsim, Removal of Arsenate from Aqueous Solution by Electro-Coagulation Method Using Al-Fe Electrodes, Int. J. Electrochem. Sci., 7, 2012, 1898 - 1907.

[27]. V.K. Gupta, S. Agarwal, PVC based 5, 10, 15, 20-tetrakis (4-methoxyphenyl) porphyrinatocobalt(II) membrane potentiometric sensor for arsenite, Talanta, 65(3), 2005, 730-734

[28]. R. D. Sharma, S. Joshi and S.Amlathe, MATLAB assisted disposable sensors for quantitative determination of arsenic, Anal. Methods, 3, 2011, 452-456

[29]. M. F. Lappert, J. D. Smith and D. R. M. Walton,Chapter 9. Organometallic compounds. Part (i) The main group elements, Annu. Rep. Prog. Chem., Sect. B: Org. Chem., 65, 1968, 283-319.

[30]. D. K. Gullstrom, and M.G.Mellon, Spectrophotometric Determination of Arsenic and Tungsten as Mixed Heteropoly AcidsAnal. Chem., 25(12), 1953, 1809- 1813

[31]. GamalAbd El-Hafeez MOSTAFA and Shaban El-Syed GHAZ, Indirect Spectrophotometric Determination of Small Amounts of Selenium(IV) and Arsenic(V) by Simple Extraction Using Flotation Columns, Analytical Sciences, 17, 2001, 1189-1193.

[32]. S. Paulo, Spectrophotometric determination of arsenic in soil samples using 2-(5-bromo-2-pyridylazo)-5-di-ethylaminophenol (BrPADAP), Ecl. Quim., 33(3),2008, 23-28. 